\title{
North West
}

\section{Map 8.2 Population density: by local or unitary authority, 2007}
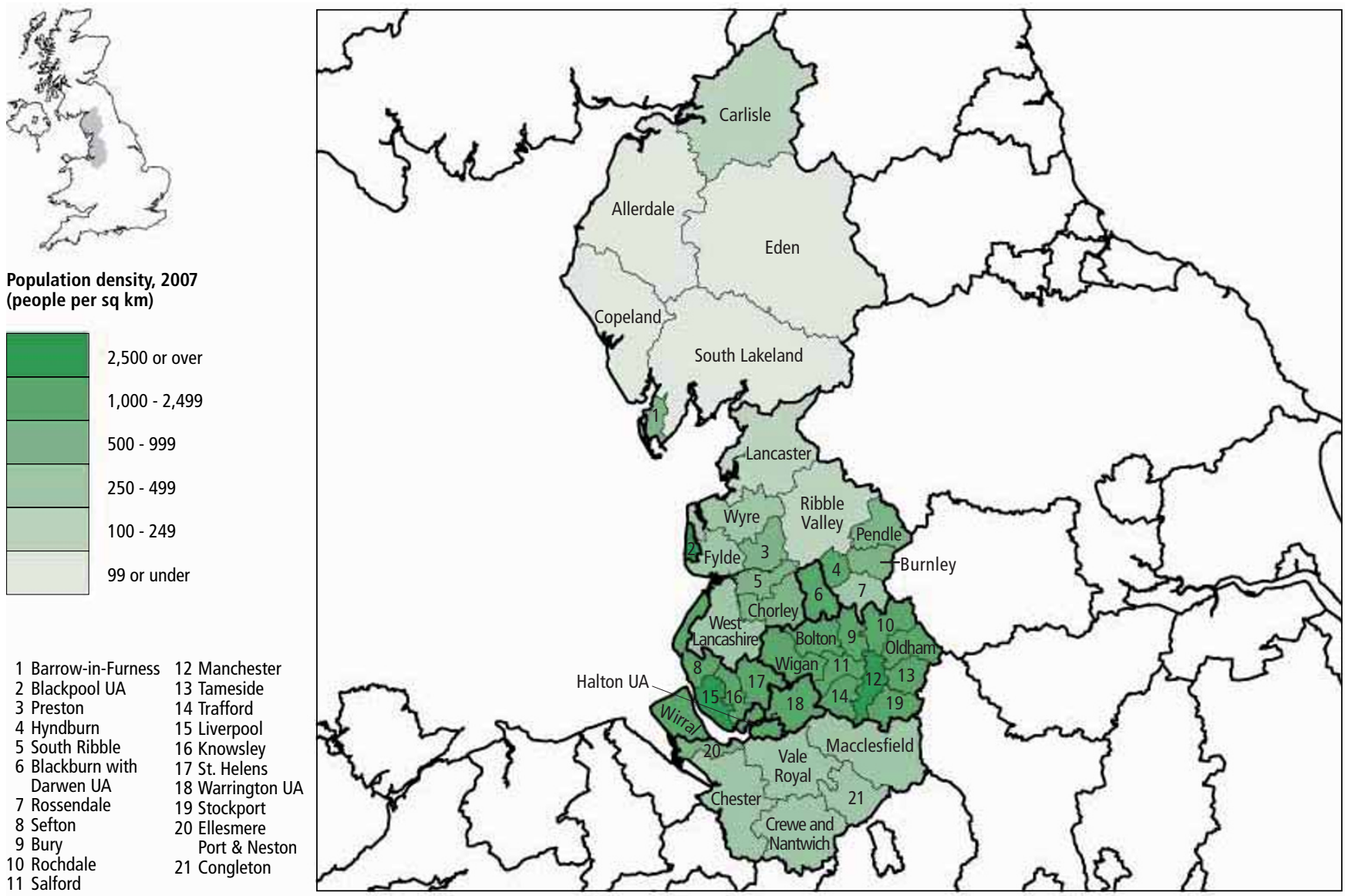

- The North West had a population of 6.9 million in mid-2007, an increase of 1.0 per cent since 1997. This compares with an overall increase of 4.6 per cent for the UK over the same period. (Online table 1.2)

- Men aged 65 in 2005-07 could expect to live another 16.6 years and women 19.3 years. This compares with 17.3 and 20.0 in the UK as a whole. (Online table 6.8)

- A higher proportion of children (18 per cent) lived in workless households in the second quarter of 2008, than the UK average of 16 per cent. (Online table 8.6)

- In the region, 60.3 per cent of pupils achieved five grades $A^{*}-C$ at GCSE level or equivalent in 2006/07, compared with 61.3 per cent for the UK as a whole. (Online table 4.8)

- The percentage of households that were victims of crime at least once in 2007/08 was 18.2 per cent, compared with an England and Wales average of 17.1 per cent. (Online table 2.1)
- People over state pension age (over 65 for males and over 60 for females) in 2007 made up 19.2 per cent of the population, compared with 19.1 per cent for the under-16s. (Online table 10.3)

- The unemployment rate stood at 6.3 per cent in the second quarter of 2008, higher than the UK rate of 5.4 per cent. (Online table 9.10)

- In April 2008, the median gross weekly earnings for full-time employees on adult rates was $f 451$, lower than the

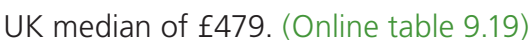

- Labour productivity (gross value added per hour worked) in 2007 was 7.8 per cent below the UK average. (Online table 3.3)

- Local authorities in the region recycled 29 per cent of household waste in 2006/07 compared with an England average of 31 per cent. (Online table 5.11) 